\title{
Urinary concentration of 3-phenoxybenzoic acid in elementary students in South Korea
}

\author{
Hye Mi Jo ${ }^{1}$, Mina $\mathrm{Ha}^{2}$, Won Jin Lee ${ }^{1,3}$ \\ ${ }^{1}$ Graduate School of Public Health, Korea University, Seoul; ${ }^{2}$ Department of Preventive Medicine, Dankook University College \\ of Medicine, Cheonan; ${ }^{3}$ Department of Preventive Medicine, Korea University College of Medicine, Seoul, Korea
}

\begin{abstract}
Objectives Pyrethroid pesticides are among the most commonly using insecticides in South Korean households and have been the subject of considerable interest among public health professionals for their potential health effects. The objective of this study is to examine the level of urinary 3-phenoxybenzoic acid (3-PBA) among elementary students in South Korea.

Methods We conducted a cross-sectional study to evaluate pyrethroid pesticide exposure levels by measuring the urinary metabolites of 3-PBA using a gas chromatographymass spectrometry method in March 2011. Study participants were 70 Asan-area and Incheon-area elementary students.

Results All respondents had values above the detection limit, and the geometric means of 3 -PBA in all children were $1.85 \mu \mathrm{g} / \mathrm{L}$ and $1.46 \mu \mathrm{g} / \mathrm{g}$ creatinine. Children with the top $10 \%$ urinary levels of 3-PBA were more likely to be girls, under nine years of age, living in a rural area, and living in a residential type apartment.

Conclusions South Korean children have a higher concentration of urinary 3-PBA compared with those of other countries. Further research identifying exposure pathways and intervention efforts to reduce environmental pesticide use are needed in South Korea.
\end{abstract}

Keywords Children, Environmental exposure, Pesticide, Pyrethroid insecticide, Urinary metabolites

\author{
Correspondence: Won Jin Lee \\ 73 Inchon-ro, Seongbuk-gu, Seoul 02855, \\ Korea. \\ Tel: $+82-2-2286-1413$ \\ Fax: +82-2-927-7220 \\ Email: leewj@korea.ac.kr \\ Received: July 11, 2015 \\ Accepted: October 12, 2015 \\ Published online: October 13, 2015 \\ This article is available from: http://e-eht.org/
}

\section{Introduction}

Pyrethroid pesticides have been used extensively worldwide to control insects in agricultural settings, commerce, public health, and individual households [1]. However, they are known to have potential health effects such as developmental neurotoxicity, immune suppression, endocrine disruption, potential carcinogenesis at high exposure levels, and dopaminergic function interference [1-3].

In South Korea (hereafter Korea), pyrethroid pesticides have been reported as among the most frequently used insecticides $[4,5]$. Children are at a greater risk than adults for non-occupational pesticide exposure, which can occur through numerous exposure pathways [6]. Biological monitoring in urine has advantages because of the ease of sample collection and is an effec- tive way to identify low-level pyrethroid metabolites. The 3-phenoxybenzoic acid (3-PBA) is a non-specific and most frequently detected urinary metabolite of major pyrethroid pesticides $[6,7]$.

Examining pesticide exposure level among children would provide important information in children's health perspectives. However, no information is currently available about pyrethroid exposure among children in Korea. The objective of this study, therefore, is to examine the level of urinary 3-PBA levels among elementary students in Korea.

\section{Materials and Methods}

\section{Study Participants}

This study used the samples collected for the pilot study of the 
Korean Environmental Health Survey in Children, which has been reported for its study design and method [8]. The participants were 37 boys and 33 girls aged 6 to 12 in elementary school among 351 children and adolescents who agreed to participate in the pilot study from two regions of Incheon (industrialized area) and Asan (rural area). Information about the children's demographic factors (e.g., birth date, sex, and age), dietary habits, current residence and household characteristics, and parents' socioeconomic information (e.g., income, occupation, and education levels) was obtained via questionnaire administered to their parents or guardians. Spot urine samples were collected from children on the morning before the survey between 9:00 and 11:00 am in March of 2011. Informed consent was obtained from both the children and their parents or guardians before enrollment. This study was approved by the institutional review board of Dankook University Hospital.

\section{Urinary Sample Collection and Analysis}

Urine samples were prepared and analyzed for 3-PBA using previously reported methods [9]. The samples were collected using $15 \mathrm{~mL}$ polystyrene conical tubes (Sarstedt AG \& Co., Numbrecht, Germany). An aliquot ( $5 \mathrm{~mL}$ ) of each urine sample was mixed with $\mathrm{HCl}$ and heated at $90^{\circ} \mathrm{C}$ for one hour. After heating, the samples were cooled, and $\mathrm{n}$-hexane and $0.1 \mathrm{M}$ $\mathrm{NaOH}$ were added to the mixture. The resulting solution was extracted and dried in a nitrogen stream. The dried samples were mixed with toluene and $\mathrm{N}$-(tert-butyldimethylsilyl)-Nmethyl-trifluoroacetamide and heated at $70^{\circ} \mathrm{C}$. After cooling the samples on ice, samples were measured by PerkinElmer Clarus 600T GC-MS (PerkinElmer, Waltham, MA, USA). Internal quality control was achieved through analysis of control urines.

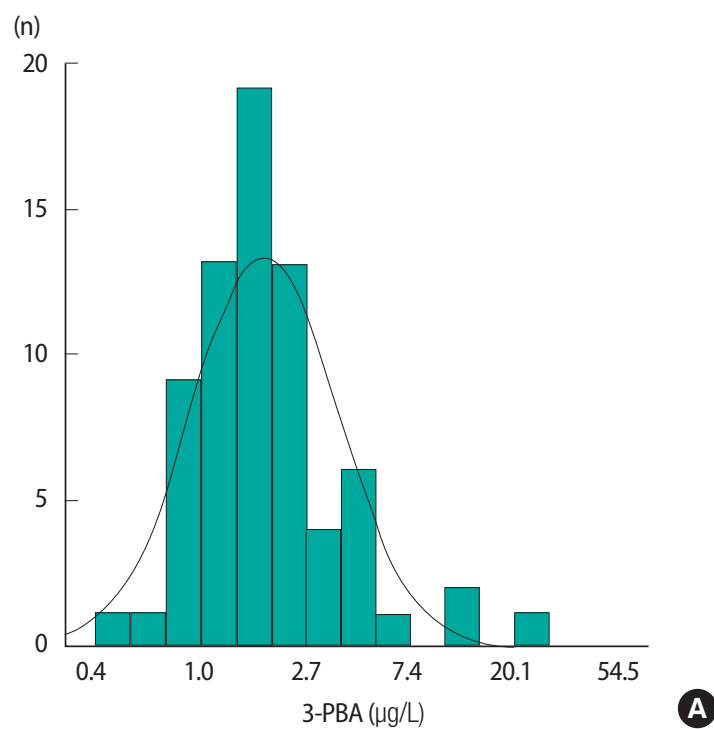

Variation coefficient was $1.1 \%$ and the limit of detection was $0.014 \mathrm{mg} / \mathrm{L}$ under study. External quality control was achieved through participation in tests of the German External Quality Assessment Scheme operated by the University ErlangenNuremberg.

\section{Data Analysis}

Deviation from the normality of the data distribution was examined using a Kolmogorov-Smirnov test. Because of the asymmetric distribution of 3-PBA, we presented the geometric mean to describe the results. The significance of the differences among individual characteristics for 3-PBA levels was estimated using non-parametric tests, i.e., the Mann-Whitney U-test and Kruskal-Wallis test. To identify the characteristics of highly exposed children, the children with the top 10\% 3-PBA concentration were also identified. A 0.05 level of probability was used as the criterion of significance (two-tailed). All data analyses were performed with SPSS version 20.0 (IBM Co., Armonk, NY, USA).

\section{Results}

The geometric mean of urinary 3-PBA concentration was 1.85 $\mu \mathrm{g} / \mathrm{L}$ (Figure 1A), and the geometric mean of creatinine-adjusted 3-PBA concentration was $1.46 \mu \mathrm{g} / \mathrm{g}$ creatinine (Figure 1B). The concentrations of 3-PBA were detected in all participants and were right-skewed for both male and female.

There was no significant difference in 3-PBA level with demographic factors, although rural children showed significantly higher mean levels of 3-PBA concentration before creatinine correction (Table 1). Children with the top $10 \%$ urinary levels

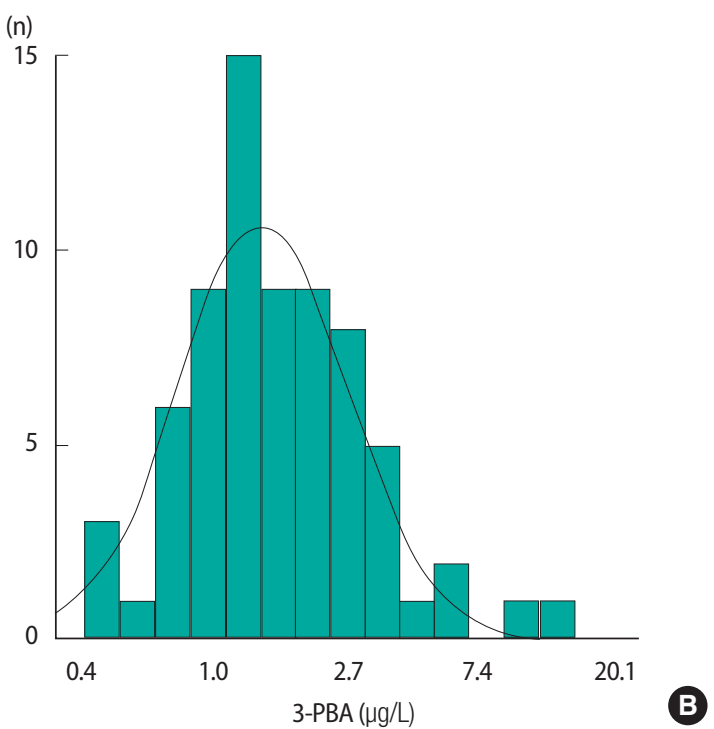

Figure 1. (A) Uncorrected geometric mean of 3-phenoxybenzoic acid (3-PBA) level ( $\mu \mathrm{g} / \mathrm{L})$, (B) creatinine-corrected geometric mean of 3-PBA level ( $\mu \mathrm{g} / \mathrm{g}$ Cr). 
Hye Mi Jo, et al. I 3-PBA level among children

Table 1. Geometric mean of urinary 3-PBA levels and sociodemographic characteristics in South Korean children

\begin{tabular}{|c|c|c|c|c|c|c|c|}
\hline \multirow{2}{*}{ Characteristics } & \multicolumn{3}{|c|}{ All children } & \multicolumn{4}{|c|}{ Children with top $10 \%$ of $3-\mathrm{PBA}$} \\
\hline & $\mathrm{n}(\%)$ & $\mu \mathrm{g} / \mathrm{L}^{\mathrm{a}}$ (GSD) & $\mu \mathrm{g} / \mathrm{g} \mathrm{Cr}^{\mathrm{b}}(\mathrm{GSD})$ & $\mathrm{n}(\%)$ & $\mu \mathrm{g} / \mathrm{L}(\mathrm{GSD})$ & $\mathrm{n}(\%)$ & $\mu \mathrm{g} / \mathrm{g} \mathrm{Cr}(\mathrm{GSD})$ \\
\hline All & $70(100.0)$ & $1.85(2.01)$ & $1.46(1.93)$ & $7(10.0)$ & $8.26(2.00)$ & $7(10.0)$ & $5.53(7.70)$ \\
\hline \multicolumn{8}{|l|}{ Sex } \\
\hline Boys & $37(52.9)$ & $1.78(1.73)$ & $1.40(1.75)$ & $2(28.6)$ & $5.39(1.16)$ & $4(57.1)$ & $3.87(1.26)^{*}$ \\
\hline Girls & $33(47.1)$ & $1.93(2.33)$ & $1.53(2.13)$ & $5(71.4)$ & $9.80(2.15)$ & $3(42.9)$ & 8.90 (1.52) \\
\hline \multicolumn{8}{|l|}{ Age (yr) } \\
\hline $6-7$ & $20(28.6)$ & $1.58(1.81)$ & $1.46(1.73)$ & $2(28.6)$ & $5.39(1.16)$ & $3(42.9)$ & $3.75(1.31)$ \\
\hline $8-9$ & $27(38.6)$ & $2.19(2.37)$ & $1.68(2.28)$ & $3(42.9)$ & $16.56(1.46)$ & $4(57.1)$ & $7.39(1.66)$ \\
\hline $10-11$ & $23(32.9)$ & $1.73(1.72)$ & $1.25(1.63)$ & $2(28.6)$ & $4.46(1.02)$ & - & - \\
\hline \multicolumn{8}{|l|}{ Area } \\
\hline Urban & $33(47.1)$ & $1.45(1.55)$ & $1.33(1.59)$ & - & - & $1(14.3)$ & 4.23 \\
\hline Rural & $37(52.9)$ & $2.30(2.26)^{\star \star}$ & $1.59(2.20)$ & $7(100.0)$ & $8.26(2.00)$ & $6(85.7)$ & $5.78(1.76)$ \\
\hline \multicolumn{8}{|c|}{ Parental education level (yr) } \\
\hline$\leq 12$ & $25(35.7)$ & $1.77(1.91)$ & $1.41(1.75)$ & $3(42.9)$ & $6.96(1.74)$ & $2(28.6)$ & $4.31(1.48)$ \\
\hline$\geq 13$ & $45(64.3)$ & $1.89(2.08)$ & $1.49(2.03)$ & $4(57.1)$ & $9.38(2.32)$ & $5(71.4)$ & $6.10(1.79)$ \\
\hline \multicolumn{8}{|l|}{ Mother's occupation } \\
\hline Non-manual worker & $37(52.9)$ & $2.02(2.12)$ & $1.61(2.00)$ & $3(42.9)$ & $11.72(2.31)$ & $5(71.4)$ & $5.51(1.70)$ \\
\hline Manual worker & $3(4.3)$ & $1.92(1.07)$ & $1.18(1.30)$ & - & - & - & - \\
\hline Unemployed & $28(40.0)$ & $1.70(1.95)$ & $1.36(1.91)$ & $4(57.1)$ & $6.36(1.70)$ & $2(28.6)$ & $5.57(2.13)$ \\
\hline \multicolumn{8}{|c|}{ Household income per month ( $\left.x 10^{4} \mathrm{KRW}\right)$} \\
\hline$<200$ & $5(7.1)$ & $2.03(2.14)$ & $1.78(1.94)$ & $1(14.3)$ & 5.97 & $1(14.3)$ & 3.26 \\
\hline $200-400$ & $31(44.3)$ & $1.64(1.89)$ & $1.33(1.73)$ & $2(28.6)$ & $7.63(2.10)$ & $3(42.9)$ & $4.98(1.16)$ \\
\hline $400-600$ & $21(30.0)$ & $2.08(2.06)$ & $1.52(2.10)$ & 2 (28.6) & $10.63(3.47)$ & $1(14.3)$ & 13 \\
\hline$>600$ & $13(18.6)$ & $1.96(2.26)$ & $1.58(2.18)$ & $2(28.6)$ & $8.17(2.08)$ & $2(28.6)$ & $5.49(2.18)$ \\
\hline \multicolumn{8}{|l|}{ Residential types } \\
\hline Detached house & $11(15.7)$ & $2.04(1.43)$ & $1.53(1.77)$ & - & - & $1(14.3)$ & 5.11 \\
\hline Apartment house & $59(84.3)$ & $1.81(2.11)$ & $1.45(1.96)$ & $7(100.0)$ & $8.26(2.00)$ & $6(85.7)$ & $5.60(1.79)$ \\
\hline \multicolumn{8}{|l|}{ Length of residence (yr) } \\
\hline$\leq 1$ & $17(24.3)$ & $1.56(1.68)$ & $1.41(1.72)$ & $1(14.3)$ & 4.41 & $1(14.3)$ & 4.23 \\
\hline $2-4$ & 37 (52.9) & $2.06(2.32)$ & $1.43(2.13)$ & $6(85.7)$ & $9.17(2.01)$ & $5(71.4)$ & $5.92(1.88)$ \\
\hline$\geq 5$ & $16(22.9)$ & $1.73(1.57)$ & $1.60(1.71)$ & - & - & $1(14.3)$ & 5.11 \\
\hline \multicolumn{8}{|l|}{ Passive smoking } \\
\hline Yes & $21(35.0)$ & $2.23(1.88)$ & $1.70(1.85)$ & $2(28.6)$ & $8.17(2.08)$ & $3(42.9)$ & $5.36(1.74)$ \\
\hline No & $39(65.0)$ & $1.74(2.20)$ & $1.43(2.06)$ & $5(71.4)$ & $8.30(2.15)$ & $4(57.1)$ & 5.65 (1.82) \\
\hline
\end{tabular}

3-PBA, 3-phenoxybenzoic acid; Cr, creatinine; GSD, geometric standard deviation; KRW, Korean won.

avolume-based concentrations ( $\mu \mathrm{g} / \mathrm{L})$.

${ }^{\mathrm{b}}$ Creatinine-adjusted concentrations ( $\left.\mu \mathrm{g} / \mathrm{g} \mathrm{Cr}\right)$.

${ }^{\star} p<0.05,{ }^{\star *} p<0.01$.

of 3-PBA were more likely to be girls, under nine years of age, living in a rural area, and living in a residential type apartment; however, only gender difference in 3-PBA level was statistically significant.

\section{Discussion}

We found that our children have a higher concentration of urinary 3-PBA compared with those of other countries, and the urinary 3-PBA level was not significantly associated with sociodemographic factors. This study provides some descriptive data for the level of urinary metabolites among children and there is a clear need to facilitate a comprehensive evaluation of non-occupational pesticide exposure in Korea.

Comparing the 3-PBA levels found in other countries, our finding was higher than that in general populations of the US $[10,11]$, Germany [12], China [13], Thailand [14], and Poland [15] but similar to that in children with farm worker family households in California $(1.97 \mu \mathrm{g} / \mathrm{g} \mathrm{Cr}$ ) (Table 2) [16]. The finding from the Korea National Environmental Health Survey in adult $(1.84 \mu \mathrm{g} / \mathrm{g} \mathrm{Cr})[17]$ was also higher than in the general populations from other countries such as the US [10], Japan [18], and Poland [19].

The high level of 3-PBA in this study may be related to frequent indoor pesticide use in Korea. Although there is no official report for using pesticide use at home, the majority of domestic insecticides on the market are known to be pyrethroid products, including permethrin and cypermethrin [5]. These pyrethroid insecticide are used at home, in apartment complex landscape gardening, and in parks and public spaces where peo- 
Table 2. Summary of previous studies for geometric mean of 3-phenoxybenzoic acid urinary levels in children

\begin{tabular}{|c|c|c|c|c|c|c|c|}
\hline Country & Author (published year) & Survey year & Children's age (yr) & No.of children & Urine collection & $\mu \mathrm{g} / \mathrm{L}^{\mathrm{a}}$ & $\mu \mathrm{g} / \mathrm{g} \mathrm{Cr}$ \\
\hline \multirow[t]{4}{*}{ United States } & Barr et al.(2010) ${ }^{c}$ & 1999-2000 & $6-11$ & 483 & Spot urine (one convenience) & 0.42 & 0.45 \\
\hline & & $2001-2002$ & $6-11$ & 580 & Spot urine (one convenience) & 0.33 & 0.42 \\
\hline & Morgan et al. (2007) & 2001 & $2-5$ & 127 & Spot urine (48 hr) & 0.39 & 0.50 \\
\hline & Trunnelle et al. (2014) & 2009 & $2-8$ & 103 & Spot urine (24 hr) & 1.11 & 1.97 \\
\hline Germany & Becker et al.(2009) ${ }^{d}$ & $2001-2002$ & $2-17$ & 363 & Spot urine (morning) & 0.31 & 0.24 \\
\hline China & Ding et al. (2012) & $2010-2011$ & $0-14$ & 180 & Spot urine (one convenience) & - & 0.39 \\
\hline Thailand & Panuwet et al. (2009) & 2007 & $12-13$ & 207 & Spot urine (morning) & 0.20 & 0.23 \\
\hline Poland & Wielgomas et al. (2013) & 2012 & $<18$ & 184 & Spot urine (morning) & 0.29 & 0.25 \\
\hline
\end{tabular}

avolume-based concentrations $(\mu \mathrm{g} / \mathrm{L})$.

${ }^{b}$ Creatinine-adjusted concentrations ( $\mu \mathrm{g} / \mathrm{g} \mathrm{Cr}$ ).

'From National Health and Nutritional Examination Survey.

'From German Environmental Survey.

ple spend time and play; these environmental exposures may contribute to increases in the level of the 3-PBA found in children in this study. In addition, as commonly used insecticides are installed in narrowly confined spaces such as living room floors and kitchens, children can consume insecticidal ingredients through hand-to-mouth activity [20]. However, because the concentration difference of 3-PBA can occur due to usage patterns of the pyrethroid pesticide, exposure pathways, and other pyrethroid metabolites $[7,12]$, further studies are needed to identify the detailed reason for the high level of 3-PBA and to reduce the pesticide exposure in homes in Korea.

We found no statistically significant differences of 3-PBA concentration with demographics. The important limitation of this cross-sectional study may hinder investigation of the differences in urinary 3-PBA levels among different demographics. Previously, some surveys showed concentration difference depending on season $[21,22]$, suggesting a possibility that pyrethroid metabolite levels in urine vary depending on the exposure or collection time. Thus, studies for characterization of this possible variability by repeated measurements according to various time and season are needed. Children's eating habits or other environmental factors as potential exposures may also influence the results [6]. Dietary intake of vegetables or fruits was also reported to be related to urinary levels of 3-PBA $[23,24]$. However, the higher proportions of rural children among the top $10 \%$ of 3-PBA and the significant increased level in rural children over urban suggest that living in a rural area may be related with high exposure to pyrethroid insecticide.

Despite of these limitations, the high level of 3-PBA concentration among children in this study emphasizes the importance of environmental pesticide exposure in Korea. Further research should examine pesticide exposures and urine collection times as well as other potential factors that may relate with 3-PBA level. It is also necessary to apply intervention efforts to reduce pesticide exposure at home in Korea.

\section{Acknowledgements}

This work was supported by the National Research Foundation of Korea (NRF) grant funded by the Korean government (MEST) (no. 2010-0021742).

\section{Conflict of Interest}

The authors have no conflicts of interest with material presented in this paper.

\section{ORCID}

Hye Mi Jo http://orcid.org/0000-0002-8070-5996
Mina Ha http://orcid.org/0000-0003-1011-9446
Won Jin Lee http://orcid.org/0000-0002-0254-7267

\section{Reference}

1. Agency for Toxic Substances and Disease Registry. Toxicological profile for pyrethrins and pyrethroids; 2003 [cited $2015 \mathrm{Jul} 1$ ]. Available from: http://www.atsdr.cdc.gov/ToxProfiles/tp155.pdf.

2. US Environment Protection Agency. Pyrethroid and pyrethrins; 2013 [cited 2015 Jul 1]. Available from: http://www.epa.gov/ oppsrrd1/reevaluation/pyrethroids-pyrethrins.html.

3. Saillenfait AM, Ndiaye D, Sabaté JP. Pyrethroids: exposure and health effects--an update. Int J Hyg Environ Health 2015;218(3):281-292.

4. Korea Occupational Safety \& Health Agency. A survey on the usage, production and importation of endocrine disrupter pesticides; 2001 [cited 2015 Jul 1]. Available from: http://www.moel.go.kr/download2.jsp?type $=/$ download_rn/20041117162249124_15708.hwp \&file=\%B3\%F3\%BE\%E0\%BA\%B8\%B0\%ED\%BC\%AD\%5B\%BA \%CE\%B7\%CF\%B9\%AB\%5D.hwp (Korean).

5. National Institute of Environmental Research. An establishment of classification system on hazardous chemicals; 2006 [cited 2015 Jul 1]. Available from: http://webbook.me.go.kr/DLi-File/NIER/06/ 168672.pdf (Korean). 
6. Morgan MK. Children's exposures to pyrethroid insecticides at home: a review of data collected in published exposure measurement studies conducted in the United States. Int J Environ Res Public Health 2012;9(8):2964-2985.

7. Egeghy PP, Cohen Hubal EA, Tulve NS, Melnyk LJ, Morgan MK, Fortmann RC, et al. Review of pesticide urinary biomarker measurements from selected US EPA children's observational exposure studies. Int J Environ Res Public Health 2011;8(5):1727-1754.

8. Ha M, Kwon HJ, Leem JH, Kim HC, Lee KJ, Park I, et al. Korean Environmental Health Survey in Children and Adolescents (KorEHS-C): survey design and pilot study results on selected exposure biomarkers. Int J Hyg Environ Health 2014;217(2-3):260-270.

9. Schettgen T, Koch HM, Drexler H, Angerer J. New gas chromatographic-mass spectrometric method for the determination of urinary pyrethroid metabolites in environmental medicine. J Chromatogr B Analyt Technol Biomed Life Sci 2002;778(1-2):121130.

10. Barr DB, Olsson AO, Wong LY, Udunka S, Baker SE, Whitehead $\mathrm{RD}$, et al. Urinary concentrations of metabolites of pyrethroid insecticides in the general U.S. population: National Health and Nutrition Examination Survey 1999-2002. Environ Health Perspect 2010;118(6):742-748.

11. Morgan MK, Sheldon LS, Croghan CW, Jones PA, Chuang JC, Wilson NK. An observational study of 127 preschool children at their homes and daycare centers in Ohio: environmental pathways to cisand trans-permethrin exposure. Environ Res 2007;104(2):266-274.

12. Becker K, Seiwert M, Angerer J, Kolossa-Gehring M, Hoppe HW, Ball M, et al. GerES IV pilot study: assessment of the exposure of German children to organophosphorus and pyrethroid pesticides. Int J Hyg Environ Health 2006;209(3):221-233.

13. Ding G, Shi R, Gao Y, Zhang Y, Kamijima M, Sakai K, et al. Pyrethroid pesticide exposure and risk of childhood acute lymphocytic leukemia in Shanghai. Environ Sci Technol 2012;46(24):1348013487.

14. Panuwet P, Prapamontol T, Chantara S, Barr DB. Urinary pesticide metabolites in school students from northern Thailand. Int J Hyg Environ Health 2009;212(3):288-297.

15. Wielgomas B, Piskunowicz M. Biomonitoring of pyrethroid exposure among rural and urban populations in northern Poland. Chemosphere 2013;93(10):2547-2553.
16. Trunnelle KJ, Bennett DH, Ahn KC, Schenker MB, Tancredi DJ, Gee SJ, et al. Concentrations of the urinary pyrethroid metabolite 3-phenoxybenzoic acid in farm worker families in the MICASA study. Environ Res 2014;131:153-159.

17. Korean Statistical Information Service. Urinary 3-PBA concentration after adjusting for creatinine levels; 2013 [cited 2015 Sep 09]. Available from: http://kosis.kr/statHtml/statHtml.do?orgId=106\&tbIId=DT_106T_01 3427\&vw_cd=MT_ZTITLE\&list_id=106_002_002\&seqNo=\&lang mode $=$ ko\&language $=$ kor\&obj_var_id $=\& i t m \_i d=\&$ conn_path $=E 1 \#$ (Korean).

18. Ueyama J, Kimata A, Kamijima M, Hamajima N, Ito Y, Suzuki K, et al. Urinary excretion of 3-phenoxybenzoic acid in middle-aged and elderly general population of Japan. Environ Res 2009;109(2):175180.

19. Wielgomas B, Nahorski W, Czarnowski W. Urinary concentrations of pyrethroid metabolites in the convenience sample of an urban population of Northern Poland. Int J Hyg Environ Health 2013;216(3):295300.

20. Tulve NS, Egeghy PP, Fortmann RC, Whitaker DA, Nishioka MG, Naeher LP, et al. Multimedia measurements and activity patterns in an observational pilot study of nine young children.J Expo Sci Environ Epidemiol 2008;18(1):31-44.

21. Lu C, Barr DB, Pearson MA, Walker LA, Bravo R. The attribution of urban and suburban children's exposure to synthetic pyrethroid insecticides: a longitudinal assessment. J Expo Sci Environ Epidemiol 2009;19(1):69-78.

22. Qi X, Zheng M, Wu C, Wang G, Feng C, Zhou Z. Urinary pyrethroid metabolites among pregnant women in an agricultural area of the Province of Jiangsu, China. Int J Hyg Environ Health 2012;215(5):487495.

23. Fortes C, Mastroeni S, Pilla MA, Antonelli G, Lunghini L, Aprea C. The relation between dietary habits and urinary levels of 3-phenoxybenzoic acid, a pyrethroid metabolite. Food Chem Toxicol 2013;52:91-96.

24. Kimata A, Kondo T, Ueyama J, Yamamoto K, Kamijima M, Suzuki $\mathrm{K}$, et al. Relationship between dietary habits and urinary concentrations of 3-phenoxybonzoic acid in a middle-aged and elderly general population in Japan. Environ Health Prev Med 2009;14(3):173179. 